\title{
Effect of bio-based flow improver on the microscopic and low-temperature flow properties of waxy crude oil
}

\author{
William Iheanyi Eke ${ }^{1}$ [D $\cdot$ Sampson Kofi Kyei ${ }^{2} \cdot$ Joseph Ajienka ${ }^{3} \cdot$ Onyewuchi Akaranta $^{1}$
}

Received: 13 September 2020 / Accepted: 22 December 2020 / Published online: 4 January 2021

(c) The Author(s) 2021

\begin{abstract}
Wax formation creates flow assurance problems in the production and transportation of waxy crude oil. Flow improvers are added to waxy crude in order to reduce handling cost. Bio-based flow improvers derived from cheap renewable resources are attractive as cost-effective, eco-friendly alternatives to the conventional additives. Natural cashew nut shell liquid extracted from waste biomass (Anacardium occidentale shells) was derivatized and applied as flow improver for waxy crude oil. Effect of the additive on wax formation in crude oil was studied by cross-polarized microscopy, while the change in oil flow properties was evaluated using a rotational coaxial cylinder viscometer. Micrographs of the waxy crude were processed and analyzed with image $\mathbf{J}$ software. The microscopic properties of the wax crystals were characterized using Feret diameter, crystal area, aspect ratio, circularity, solidity and boundary fractal dimension. The pour point of doped crude oil was depressed by $-18{ }^{\circ} \mathrm{C}$ and the wax area fraction reduced by $40 \%$ due to wax inhibitive effect of the additive. The presence of the additive resulted in evolution of smaller, rounder and more regular wax crystals with smoother and more even surfaces indicated by reduction in the Feret diameter, aspect ratio and boundary fractal dimension of wax crystals in doped oil, and an increase in crystal circularity and solidity. The shear stress and viscosity of doped oil were reduced by $86.8 \%$ and $85.0 \%$, respectively. The flow improvement effect of the CNSL derivative is linked to its effect on morphology and microstructure of wax crystals in the crude oil.
\end{abstract}

Keywords Cashew nut shell liquid · Flow improver · Pour point depressant · Waxy crude oil · Wax crystal morphology · Paraffin

\section{Introduction}

Wax precipitation and deposition is a major flow assurance problem in the production and transportation of waxy crude oil, especially in deep-water developments (Sarica and Panacharoensawad 2012). Due to sensitivity of paraffins to temperature change, high molecular weight n-alkanes precipitate from crude oil as the oil temperature decreases and with the loss of solubilizing light-end hydrocarbons to the

William Iheanyi Eke

eke.iheanyi@aceuniport.org

1 World Bank-Africa Centre of Excellence for Oilfield Chemicals Research, University of Port Harcourt, Port Harcourt, Nigeria

2 Department of Chemical Engineering, Kumasi Technical University, Kumasi, Ghana

3 Department of Petroleum Engineering, University of Port Harcourt, Port Harcourt, Nigeria gas phase (Fasesan and Adewunmi 2006;). Wax crystallization begins with the formation of stable nuclei consisting of clusters of paraffin molecules, followed by crystal growth as increasing number of paraffin molecules attach themselves to the nuclei, and finally agglomeration (Lashkarbolooki et al. 2011; Mozaffari et al. 2015). Wax precipitation changes oil flow properties, increasing oil viscosity and the risk of gelation (Odutola and Idemili 2020). This results in higher energy requirement to pump oil and difficulty in restarting flow if oil gels, due to high yield stress of wax gel (Ajienka and Ikoku 1990; Mozaffari et al. 2017). Mitigation of wax by addition of pour point depressants/flow improvers sustains flow and helps to reduce the frequency of expensive wax remedial operations such as pigging (Wang et al. 2015). Therefore, addition of pour point depressants to crude oil has been adopted as a reliable and cost-effective method to control the formation of wax and manage the attendant flow assurance problems (Sun et al. 2020; Ridzuan et al. 2020; Theyab 2018).Conventional pour point depressants 
encompass a broad spectrum of molecules, mostly polymers, which interact with paraffin in crude oil in a manner disruptive to the wax crystal habit via one or more mechanisms including nucleation, co-crystallization, adsorption and dispersion (Sun et al. 2020; Hao et al. 2019; Wei 2015; Yang et al. 2014; Zhang et al. 2003). The cost of PPD injections, their selectivity to crude oil and growing interest in eco-friendly oilfield chemicals are major motivations for research aimed at developing low-cost, bio-based, green additives for crude oil flow improvement (Ragunathan et al. 2020). There are a number of reports on the use of plant extracts, raw vegetable oils and their derivatives, pristine natural cashew nut shell liquid, as well as derivatives of natural and technical cashew nut shell liquid as wax inhibitors and pour point depressants/flow improvers for waxy crude oil (Ragunathan et al. 2020; Azeem et al. 2020; Eke et al. 2019b, 2020; Akinyemi et al. 2018; Huyen and Khanh 2014; Deng et al. 2016; Kumar et al. 2015; Banerjee et al. 2015; Huyen et al. 2012; Chen et al. 2011). This work further explores the potential of utilizing cashew nut shell liquid as crude oil pour point depressant by developing and evaluating a new, low-cost cashew nut shell liquid derivative. This is important as bio-based flow improvers have proven to be efficient alternatives to the conventional synthetic polymer PPDs. In addition, being based on renewables, they are also more eco-sustainable. Cashew nut shell liquid is particularly attractive as a renewable raw material for industrial-scale preparation of PPDs because it is not a food source; it is cheap and easily extracted with good yield from the cashew nut shell waste biomass (Gandhi et al. 2012; Tyman et al. 1989). Cashew nut shell liquid is a mixture of structurally related alkyl/alkenyl phenols: anacardic acid (6-pentadecyl salicylic acid), cardanol (3-pentadecyl phenol), cardol (5-pentadecyl resorcinol) and 2-methyl cardol (2-methyl5-pentadecyl resorcinol). The mixture is primarily anacardic acid (natural CNSL) if it is obtained by solvent extraction using low-boiling solvents or cardanol (technical CNSL) if obtained by pyrolysis of the shell (Gandhi et al. 2012; Tyman 1976). In this paper, we report the preparation and evaluation of a sulfonated cashew nut shell liquid esteramine as flow improver for waxy crude oil. Effect of the natural cashew nut shell liquid derivative on wax formation and wax crystal properties was studied by cross-polarized microscopy, while its effect on oil flow properties was evaluated by viscometry.

\section{Materials and methods}

\section{Materials}

Diethanolamine (BDH Chemicals); acetone; xylene (industrial grade); dichloromethane (HPLC grade; Sigma-Aldrich)
Niger-Delta waxy crude oil (well-head sample from a swamp field. Donated by Shell Petroleum Development Company, Port Harcourt). The physico-chemical properties of the crude oil are presented in Table 1.

\section{Determination of paraffin carbon number distribution}

Paraffin carbon number distribution of crude oil sample and wax precipitate was determined by gas chromatography (GC) according to ASTM D3328 using an Agilent 7890A gas chromatograph. $1 \mu \mathrm{l}$ of crude oil sample was autoinjected at an inlet temperature and pressure of $250{ }^{\circ} \mathrm{C}$ and $18.54 \mathrm{psi}$, respectively. Flow rate of carrier gas and sample were $0.455 \mathrm{ml} / \mathrm{min}$ and $15.0 \mathrm{~cm} / \mathrm{sec}$, respectively. The column was a $50 \mathrm{~m}$ long capillary column with internal diameter of $0.2 \mathrm{~mm}$ and film thickness of $0.5 \mu \mathrm{m}$, at a maximum oven temperature of $325^{\circ} \mathrm{C}$. The eluates were detected on a flame ionization detector (FID) maintained at column temperature. The experimental conditions for the analysis of the wax precipitate were identical to the oil sample. First, the wax fraction of the crude oil was obtained by the modified UOP 46-64 method (without the oil clarification step). The wax precipitate was dried and then redissolved in HPLC grade dichloromethane (DCM) prior to GC analysis.

\section{Extraction and derivatization of natural cashew nut shell liquid}

Cashew nut shell liquid was extracted from cashew nut shell using acetone as described in the literature (Eke et al. 2019b). Cold extraction of CNSL or extraction using lowboiling solvents gives a liquid containing $65-90 \%$ anacardic acid (Ghandi et al. 2012; Tyman 1976; Gedam and Sampthkumaran 1986).

Table 1 Physico-chemical properties of crude oil sample

\begin{tabular}{lll}
\hline Property & Crude oil & Ref. method \\
\hline Specific gravity $\left(15{ }^{\circ} \mathrm{C}\right)$ & 0.821 & ASTM D1298-12b \\
API gravity & 40.9 & \\
Kinematic viscosity $\left(40{ }^{\circ} \mathrm{C}\right) \mathrm{cSt}$ & 2.20 & ASTM D 455-12 \\
Kinematic viscosity $\left(100^{\circ} \mathrm{C}\right)$ & 1.12 & \\
$\quad \mathrm{cSt}$ & & \\
WAT $\left({ }^{\circ} \mathrm{C}\right)$ & 26.6 & ASTM D 5772 \\
Pour point $\left({ }^{\circ} \mathrm{C}\right)$ & 15 & ASTM D 5853-17-A \\
Wax content $(\%)$ & 13.2 & UOP 46-64 \\
Water content $(\%)$ & 0.025 & ASTM D 4006-11 \\
Asphaltene content $(\%)$ & 0.09 & ASTM D 6560 \\
Saturates $(\%)$ & 56.3 & Column chromatography \\
Aromatics $(\%)$ & 39.8 & \\
Resins $(\%)$ & 2.00 & \\
\hline
\end{tabular}


Natural cashew nut shell liquid (CNSL) was modified with diethanolamine and subsequently sulfonated using sulfuric acid as follows:

CNSL (100 ml) was mixed with $27.2 \mathrm{ml}$ diethanolamine (DEA) representing CNSL/DEA ratio of 1:1.The mixture was heated to $110-130^{\circ} \mathrm{C}$ for $40 \mathrm{mins}$ and water of esterification collected in a Dean-Stark trap. Sulfamic acid was used as catalyst. In total, $48 \mathrm{ml}$ of the diethanolamine-modified CNSL was placed in an ice-bath for $45 \mathrm{mins}$ till it cooled to $2{ }^{\circ} \mathrm{C}$. In total, $8.4 \mathrm{ml}$ of sulfuric acid was added to the diethanolamine-modified CNSL drop-wise with constant stirring (approximately 3parts by weight of diethanolamine-modified CNSL to 1part of $\mathrm{H}_{2} \mathrm{SO}_{4}$ ). The temperature of the system was constantly monitored and kept below $30^{\circ} \mathrm{C}$. The derivative was labeled CNX. The spectra of CNX, diethanolaminemodified CNSL, diethanolamine and natural CNSL were recorded using a Fourier transform infrared spectrophotometer (FTIR). Finally, CNX was blended with xylene to obtain a $75 \% \mathrm{v} / \mathrm{v}$ solution of CNX in xylene. The formulation was used for the evaluation tests.

\section{Performance evaluation of CNSL derivative}

\section{Pour point}

The crude oil sample was warmed up in a water bath to $60{ }^{\circ} \mathrm{C}$, to dissolve any pre-existing wax and then doped with the additive at $500 \mathrm{ppm}, 1000 \mathrm{ppm}, 2000 \mathrm{ppm}, 4000 \mathrm{ppm}$ and $5000 \mathrm{ppm}$ using a Hamilton Co. micro-syringe. Pour point test jar filled to mark $(40 \mathrm{ml})$ with crude oil sample was re-corked and thermometer inserted. The test jar was then placed in the cooling jacket of a Stanhope-Seta cloud $\&$ pour point refrigerator. Pour point was determined according to ASTM D 5853-17a- Standard Test Method for Pour Point of Crude Oils (Procedure A). The pour point test jar was gently extracted from the cooling jacket every $3{ }^{\circ} \mathrm{C}$ drop in temperature and observed for flow. $3{ }^{\circ} \mathrm{C}$ was added to the temperature at which the oil ceased to flow and recorded as the pour point. Neat and doped oil samples were handled in an identical manner. The optimal dosage of additive for maximum pour point depression was determined. The crude oil samples subsequently used for microscopy and viscometric studies were doped at the optimal additive dosage.

\section{Cross-polarized microscopy}

Optical microscopy study of wax formation in the crude oil was carried out using an Olympus BX51 cross-polarized microscope equipped with a Linkam THMS 600 thermal stage capable of temperature range and heating rate of $-196{ }^{\circ} \mathrm{C}$ to $600{ }^{\circ} \mathrm{C}$ and $0.01-130{ }^{\circ} \mathrm{C} / \mathrm{min}$, respectively. Quartz sample holder was half-filled with five drops of crude oil sample and inserted into the heating block niche. Temperature control and data capture were automated. The process was controlled by Linksys 32 software system via T95-linkpad system controller. Temperature program involved an initial heating cycle at a rate of $5{ }^{\circ} \mathrm{C} / \mathrm{min}$ to a maximum temperature of $60{ }^{\circ} \mathrm{C}$, a hold-time of $1 \mathrm{~min}$, followed by the cooling cycle at a rate of $1{ }^{\circ} \mathrm{C} / \mathrm{min}$ to a minimum temperature of $10^{\circ} \mathrm{C}$. The stage was cooled with liquid nitrogen and water via LNP95 liquid nitrogen pump and Eheim professional water circulating pump, respectively. An identical heating/cooling program was adopted for neat and doped oil samples. Prior to the analysis, the doped sample was warmed to $60^{\circ} \mathrm{C}$ in water bath and mixed with additive at the pre-determined dosage for optimal pour point depression. The crystallization process was monitored on a live feed and still images were captured automatically every 30second with a pixelink 1394 digital camera. The micrographs were processed with image $\mathbf{J}$ software as shown in Fig. 1. The micrographs were analyzed after processing to determine the microscopic properties of the wax crystals. The crystal parameters of interest were crystal size (Feret diameter, area); area fraction, circularity; solidity and boundary fractal dimension. The boundary fractal dimension was determined by box-counting method using default software box sizes of 2, 3,4,6,8,12,16,32 and 64 .

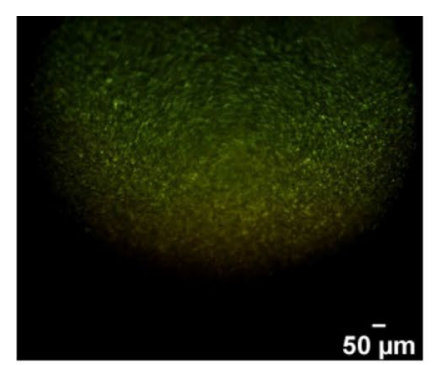

(a)

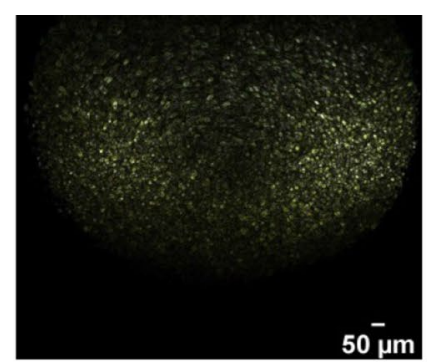

(b)

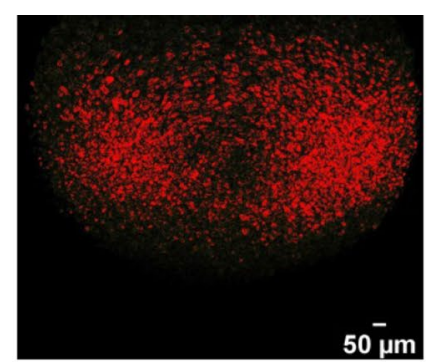

(c)

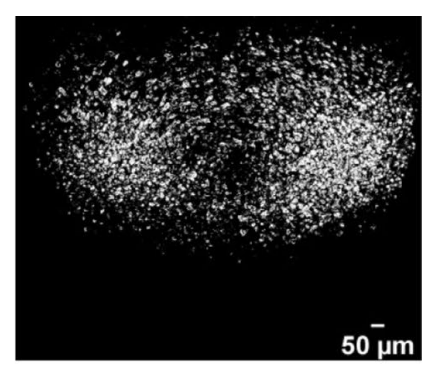

(d)

Fig. 1 Scheme for micrograph processing on Image J: raw micrograph (a); crystal edge definition (b); image thresholding (c); conversion to binary image (d) 


\section{Viscometry}

Effect of the additive on viscosity of crude oil was studied using an Ofite (900) coaxial cylinder rotational viscometer. The crude oil sample was warmed to $60{ }^{\circ} \mathrm{C}$ in a water bath, doped with additive and transferred to viscometer cup. The shear stress and viscosity of the oil were measured at 5-20 rpm intervals between 10 and $100 \mathrm{rpm}$ corresponding to shear rates of $17 \mathrm{~s}^{-1}, 25 \mathrm{~s}^{-1}, 34 \mathrm{~s}^{-1}, 43 \mathrm{~s}^{-1}, 51 \mathrm{~s}^{-1}, 76 \mathrm{~s}^{-1}$, $102 \mathrm{~s}^{-1}, 136 \mathrm{~s}^{-1}$ and $170 \mathrm{~s}^{-1}$ respectively, at temperature intervals of $5{ }^{\circ} \mathrm{C}$ from $50{ }^{\circ} \mathrm{C}$ to $10^{\circ} \mathrm{C}$.

\section{Results and discussion}

\section{Paraffin composition of crude oil sample and wax precipitate}

The crude oil assay shows that it is a light paraffinic oil with moderate wax content and low asphaltene $\left(\mathrm{C}_{7}\right.$ insolubles) content (Table 1). The gas chromatograms of the oil and wax precipitate are shown in Fig. 2. Analysis of the chromatograms indicates that the oil and wax precipitate have mode paraffin carbon number of $n-C_{15}$ and $\mathrm{n}-\mathrm{C}_{27}$, respectively (Fig. 3). The wax precipitate consists of $n-C_{21+}$ paraffins with an average carbon number of 26. The crystallization of this fraction in oil negatively affects oil flowability. The n-paraffin composition of the crystallized wax differs from the $n-C_{21+}$ composition of the oil due to variations in the degree of crystallization

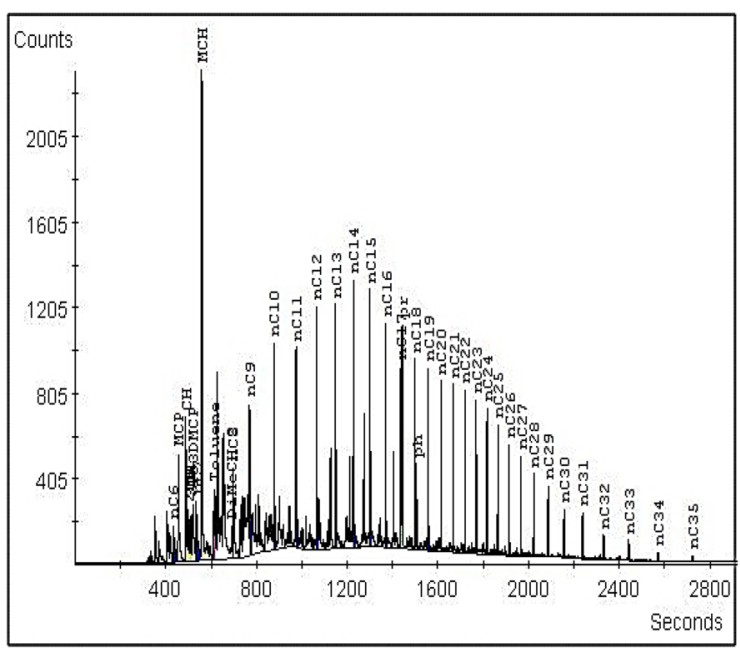

(a)

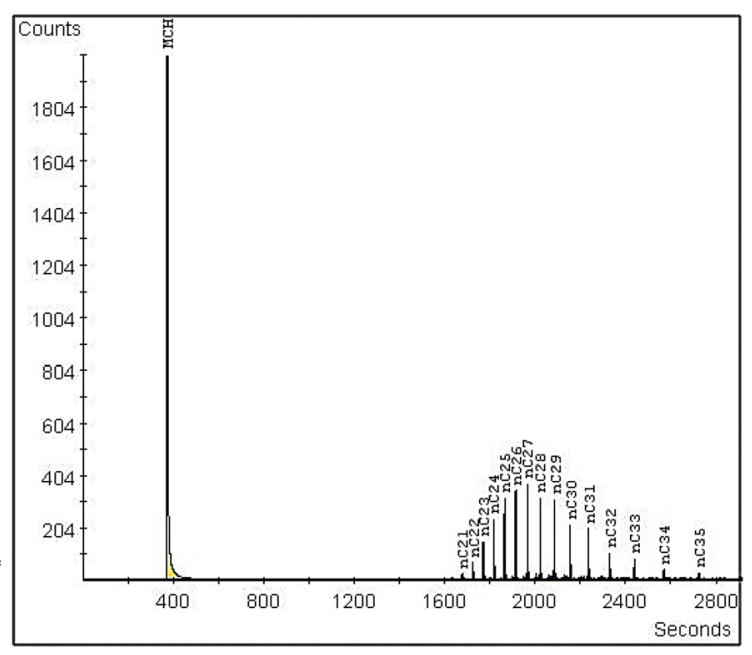

(b)

Fig. 2 Chromatogram of crude oil (a) and crystallized wax (b)

Fig. 3 Paraffin carbon number distribution of crude oil and crystallized wax

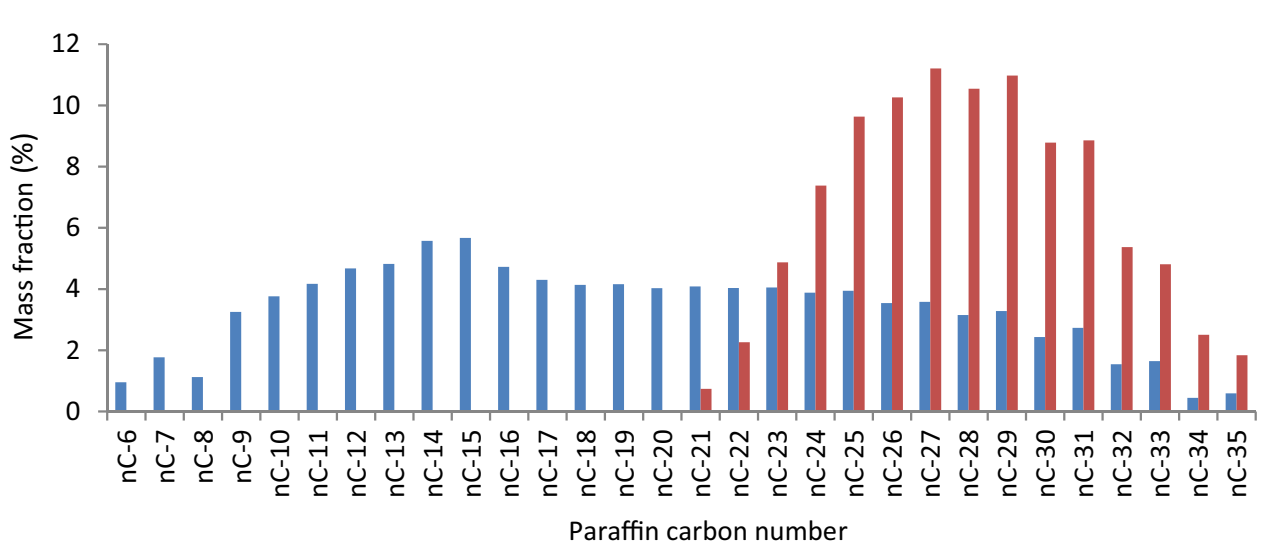


of individual carbon numbers. This is further signified by a shift in the mode paraffin carbon number of $\mathrm{n}-\mathrm{C}_{21+}$ fractions from $n-C_{23}$ in the oil to $n-C_{27}$ in crystallized wax. Studies have reported that the n-paraffin composition of wax influences its crystal morphology and microstructure and response of the oil to treatment with flow improvers (Paso et al. 2005; Bai and Zhang 2013, Garcia et al. 2000). A number of factors have been adduced in the literature to affect the crystallization of paraffin carbon numbers, including alkane chain length (molecular weight), interactions between neighboring alkane carbon numbers as well as between alkane carbon numbers and asphaltenes and resins in the crude oil (Kriz and Andersen 2005; Senra et al. 2008; Eke et al. 2019a).

\section{Derivatization of natural cashew nut shell liquid}

Figure 4 shows the FTIR spectra of natural CNSL and DEA (Diethanolamine), while Fig. 5 shows the spectra of diethanolamine-modified CNSL and the sulfonated CNSLesteramine (CNX). Together, the two figures highlight the CNSL modification process. The broad band at $3283.8 \mathrm{~cm}^{-1}$ in the spectrum of CNX originated from the phenolic $\mathrm{O}-\mathrm{H}$ vibration of CNSL. The N-H stretch of secondary amine originally occurring at $3291.2 \mathrm{~cm}^{-1}$ in the spectrum of diethanolamine is also contained in this broad band. Likewise, the bands at $3011.7 \mathrm{~cm}^{-1}$ are due to $=\mathrm{C}-\mathrm{H}$ stretching in the 15-carbon aliphatic chain of CNSL. This band is further confirmed by $=\mathrm{C}-\mathrm{H}$ deformation (bending) vibrations occurring at $708.2 \mathrm{~cm}^{-1}$ in natural CNSL and at $693.3 \mathrm{~cm}^{-1}$ in CNX (Figs. 4 and 5). The slight shift in frequency is likely

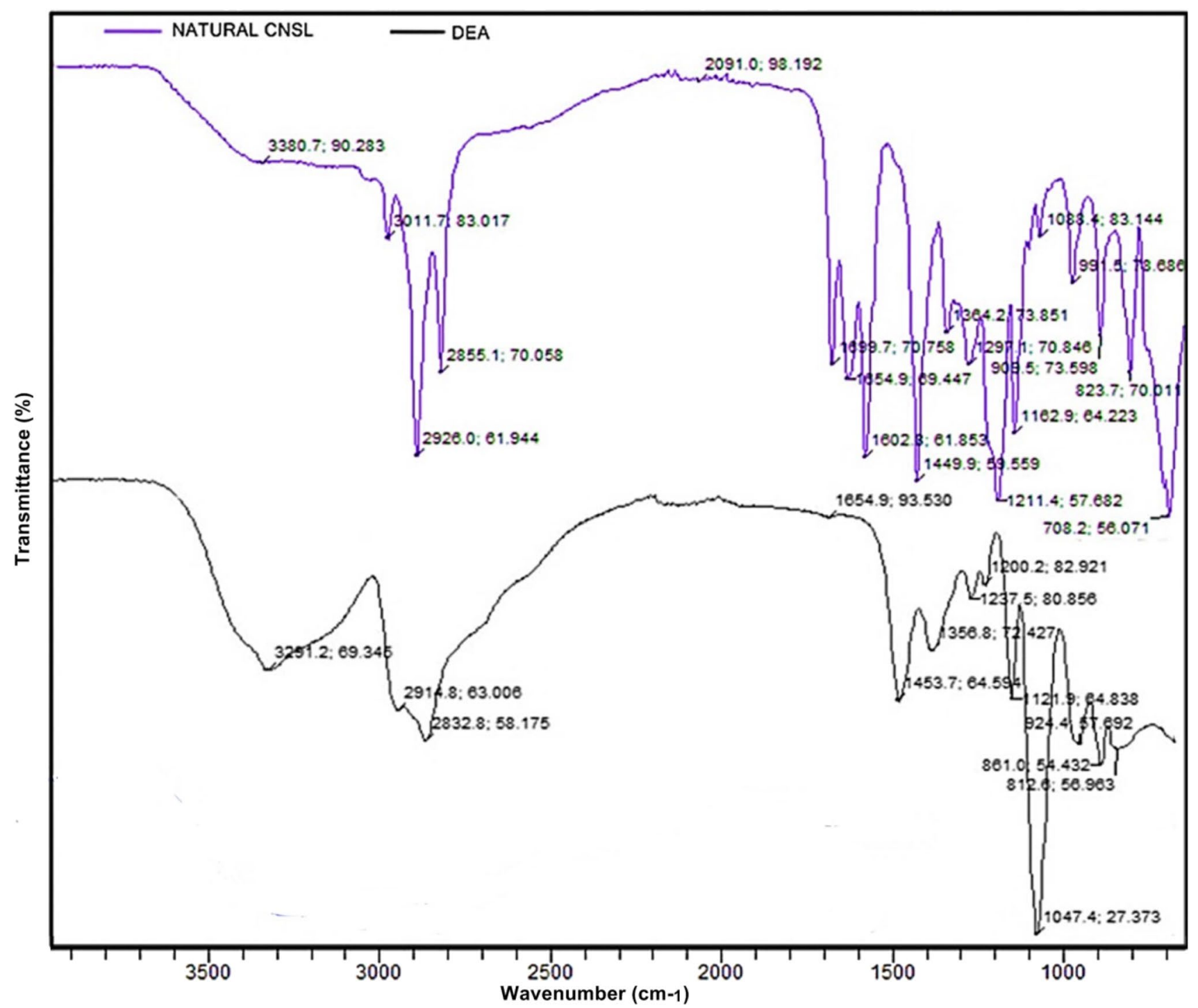

Fig. 4 FTIR spectra of natural CNSL and DEA 


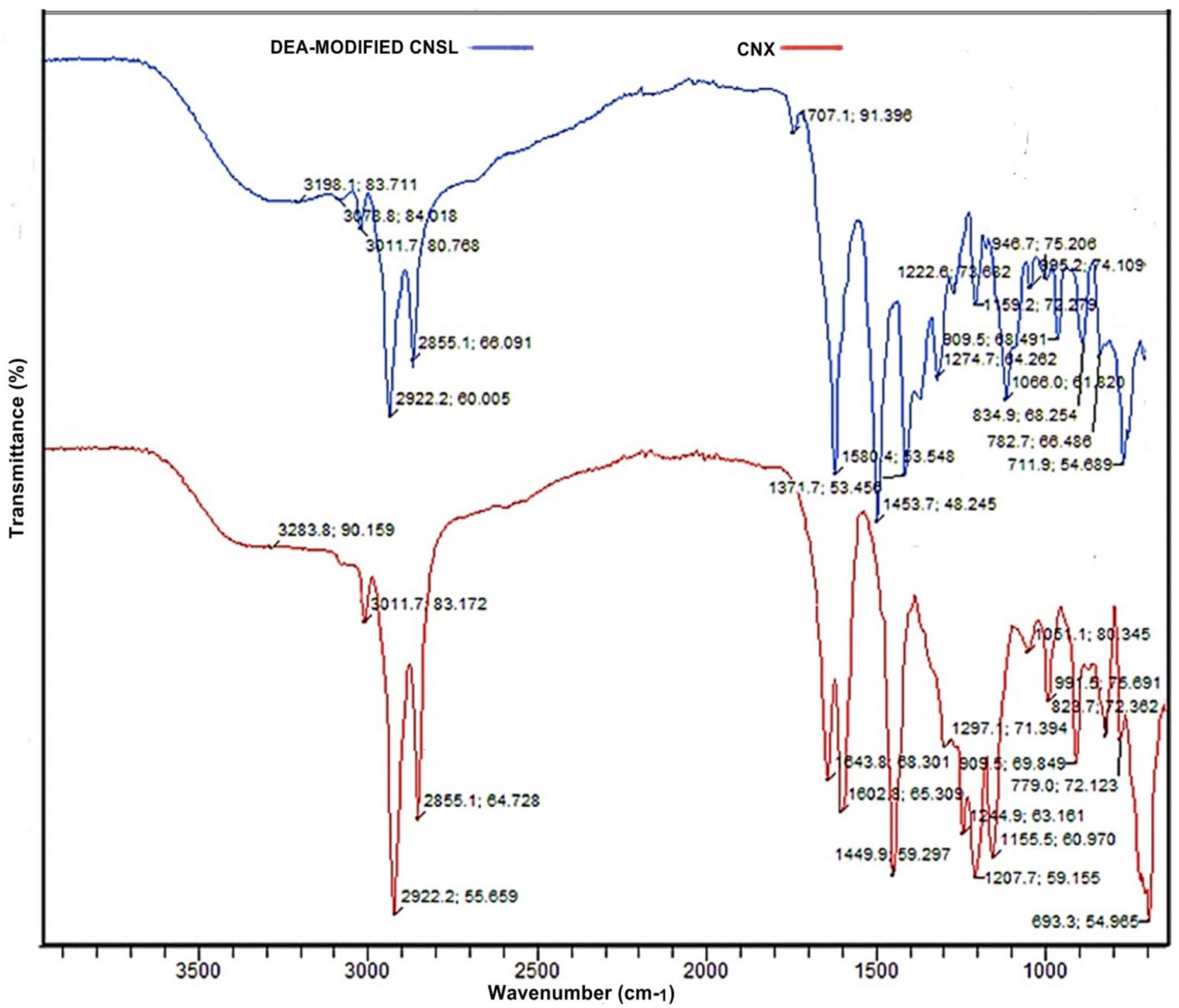

Fig. 5 FTIR spectra of DEA-modified CNSL and CNX

due to the change in chemical environment in the sulfonated CNSL-esteramine. Also, $2922.0 \mathrm{~cm}^{-1}$ and $2855.1 \mathrm{~cm}^{-1}$ correspond to $\mathrm{C}-\mathrm{H}$ vibrations of methylene and methyl groups of the 15-carbon chain of CNSL occurring at $2926.0 \mathrm{~cm}^{-1}$ and $2855.1 \mathrm{~cm}^{-1}$, respectively, in the spectrum of natural CNSL. Methyl C-H stretch vibration of the aliphatic chain of CNSL is confirmed by the deformation vibrations at $1449.9 \mathrm{~cm}^{-1}$ in the spectrum of CNX (Fig. 5).

The bands at $1580.4-1602.8 \mathrm{~cm}^{-1}$ are likely due to $\mathrm{C}=\mathrm{C}$ stretch of benzene group of anacardic acid (Figs. 4 and 5). The sharp band at $1699 \mathrm{~cm}^{-1}$ in the spectrum of natural CNSL is the $\mathrm{C}=\mathrm{O}$ of carboxylic acid (attached to aromatic ring) and is confirmed by the $\mathrm{C}-\mathrm{O}$ stretch vibrations of the acid $1211.4 \mathrm{~cm}^{-1}$ (Fig. 4). This band disappears after modification, while new bands appearing at $1274.7 \mathrm{~cm}^{-1}$ and $1244.9 \mathrm{~cm}^{-1}$ in the spectra DEA-modified CNSL and
CNX, respectively, are likely due to $\mathrm{C}-\mathrm{O}$ vibrations of ester (Fig. 5). This suggests the conversion of acid groups of CNSL to ester linkages with DEA. The diminution of the strong sharp $\mathrm{C}-\mathrm{O}$ vibration of primary alcohol groups of DEA, occurring at $1047.4 \mathrm{~cm}^{-1}$ in the spectrum of DEA and $1066 \mathrm{~cm}^{-1}$ in the spectrum of DEA-modified CNSL, supports this observation. The new band at $1155.5 \mathrm{~cm}^{-1}$ in the spectrum of $\mathrm{CNX}$ corresponds to $\mathrm{S}=\mathrm{O}$ stretch vibrations of sulfonic acid group.

\section{Effect of CNSL derivative on crude oil pour point}

Table 2 shows that the effect of the sulfonated cashew nut shell liquid esteramine (CNX) on pour point of the crude oil is dosage-dependent. Pour point depression effect increased with dosage up to an optimal dosage of $1000 \mathrm{ppm}$, with 
Table 2 Effect of CNX dosage on crude oil pour point

\begin{tabular}{lllllll}
\hline Dosage $(\mathrm{ppm})$ & 0 & 500 & 1000 & 2000 & 4000 & 5000 \\
\hline Pour point $\left({ }^{\circ} \mathrm{C}\right)$ & 15 & 6 & -3 & 0 & 0 & 0 \\
\hline
\end{tabular}

maximum pour point depression of $-18{ }^{\circ} \mathrm{C}$. Above this optimal dosage, the additive has no significant effect on the pour point.

\section{Effect of CNSL derivative on wax crystal morphology}

Figure 6 presents the optical micrographs of neat crude oil sample and crude oil sample doped with $1000 \mathrm{ppm}$ of CNX, taken as the oil cooled. It shows the evolution of wax crystals in the oil in the absence and presence of the sulfonated cashew nut shell liquid esteramine (CNX). Wax crystals in the crude oil doped with 1000 ppm of CNX are visibly smaller than those in the neat oil. Table 3 presents the microscopic properties of wax crystals as a function of temperature and PPD addition. The average Feret diameter is a measure of crystal size, computed as the square root of product of maximum and minimum caliper diameter of wax crystals. Wax crystal size increases as the temperature of the oil decreases. Aspect ratio (ratio of the major axis to the minor axis of the crystal) describes the wax crystal shape. The minimum aspect ratio of 1 denotes a perfectly round crystal. Higher aspect ratio values indicate an elongated rod-like morphology. Circularity is a perimeter-dependent parameter and reflects the degree of crystal regularity. Higher circularity indicates higher crystal regularity. A maximum circularity value of 1.0 indicates a perfect circle. Solidity and boundary fractal provide a quantitative measure of wax crystal microstructure. Crystal solidity is the ratio of the area of the crystal to its convex hull area. Low solidity value indicates a ruffled, uneven crystal surface, while increasing boundary fractal dimension implies greater crystal surface roughness. Table 3 shows that not only does wax crystal size increase as temperature decreases, the crystals also become more rodlike in shape. The surfaces of the crystals also become ruffled and wrinkled and the edges become increasingly rough. The changes in the wax crystal morphology are probably due to rapid crystal growth as new paraffin chains fall out of solution and attach themselves to the wax nuclei, as well as the agglomeration of crystals in the oil. The evolution of large, rod-like crystals with ruffled surfaces increases the ability of the wax crystal to overlap and interlock with each other. Nanoscale roughness provides anchor points on crystal surface for crystal-crystal interlocking (Paso et al. 2005). These conditions facilitate crystal networking and favor the formation of strong wax networks in oil resulting in poor oil flowability at low temperature. These changes in the wax crystal morphology and microstructure explain the difficulty in handling wax oil at low temperature where the flowability of the oil progressively decreases with decreasing temperature to the point of oil gelation. In the presence of CNX, the size, aspect ratio and boundary fractal dimension of wax crystals are reduced, while crystal circularity and solidity increases (Table 3). Wax crystals in doped oil are smaller and rounder in shape with more even, smoothened surfaces. This suggests that the additive has some influence on wax agglomeration as well as growth of the incipient wax crystals and that its action mechanism involves wax crystal dispersion. The wax crystal size, aspect ratio and solidity distributions shown in Figs. 7, 8 and 9, respectively, are useful in elucidating the effect of the additive on wax crystal evolution. The error bars indicate the experimental standard deviation. Irrespective of temperature, the crystal size distribution is dominated by crystals $<20 \mu \mathrm{m}^{2}$, indicating that new wax nuclei are formed as existing crystals grow in the cooling oil (Fig. 7). The distribution shifts to larger size range with decreasing temperature. This is due to crystal growth and agglomeration. As temperature of the oil decreases, more paraffin molecules precipitate due to loss of solubility. These precipitated paraffins attach to wax nuclei already existing in the oil resulting in crystal growth. As they grow, wax crystals in oil also interconnect with each other forming large agglomerates. The presence of CNX in the oil hinders the evolution of large crystals resulting in a relatively higher proportion of crystals in mid-sized ranges $\left(50-100 \mu \mathrm{m}^{2}\right)$. This effect is likely due to wax dispersion by additive molecules (Fig. 7). Similarly, the aspect ratio distribution shifts to the left in doped oil, favoring rounder crystals (Fig. 8). Crystal roundness is the reciprocal of the aspect ratio. In the neat oil, the greatest number of perfectly round crystals (aspect ratio of 1) is found at $20^{\circ} \mathrm{C}$. The observation that crystal aspect ratio increases with decreasing temperature is in agreement with the findings by Taheri-Shakib et al. 2018 , indicating that wax crystals become elongated and more rod-like as the temperature of waxy crude oil decreases. Generally, the mode aspect ratio of the crystals is in the range 1-2 irrespective of oil temperature and the presence of additive. Notably, the proportion of rounder wax crystals (aspect ratio $\leq 2$ ) increases on doping with CNX, while the proportion of more elongated crystals (aspect ratio $\geq 3$ ) decreases relative to the neat oil. The aspect ratio of wax crystals in doped oil at $20{ }^{\circ} \mathrm{C}$ is limited to a maximum value of 5 , whereas crystals with high aspect ratio up to 9 exist in the neat oil (without CNX). The same can be observed at lower temperatures $\left(15^{\circ} \mathrm{C}\right.$ and $\left.10{ }^{\circ} \mathrm{C}\right)$, except for a small proportion of crystals in doped oil with aspect ratio of about 6 and 8 . Wax crystals in the cooling crude oil

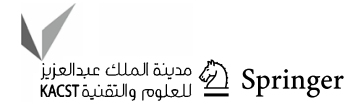



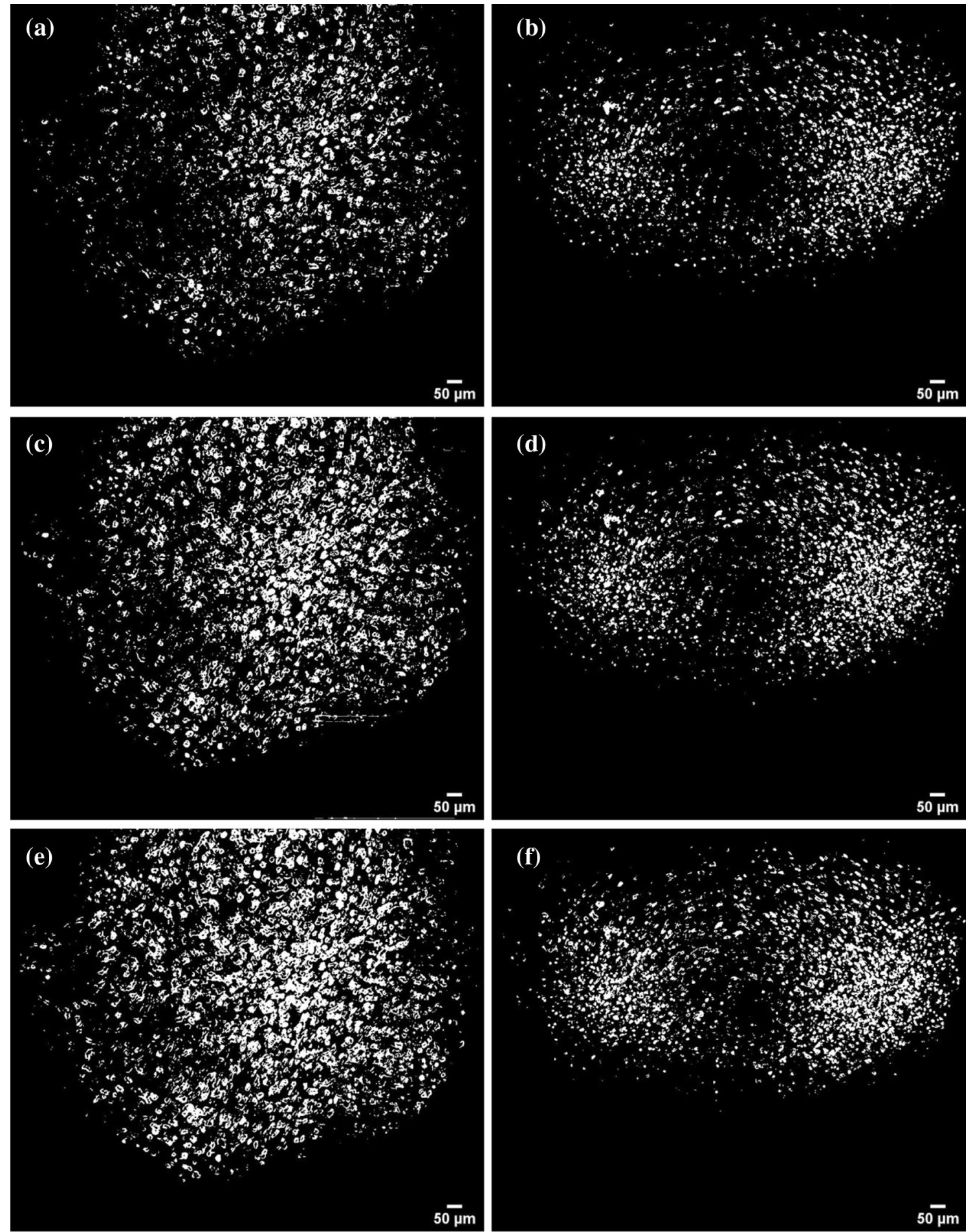

Fig. 6 Micrographs of crude oil at $20{ }^{\circ} \mathrm{C}, 15^{\circ} \mathrm{C}$ and $10{ }^{\circ} \mathrm{C}$. Neat crude oil sample and crude oil doped with $1000 \mathrm{ppm}$ of $\mathrm{CNX}$ are labeled (a); (c); (e) and (b); (d); (f), respectively

sample can be placed in two groups in terms of solidity: crystals of low solidity $(\leq 0.7)$ and crystals of high solidity $(\geq 0.8)$ (Fig. 9). As temperature of the neat oil decreases the proportion of low solidity crystals increases at the expense of high solidity crystals, resulting in a preponderance of crystal with ruffled surfaces in the oil at low temperature. A small number of highly ruffled crystals $(0.3-0.4)$ were observed at $15{ }^{\circ} \mathrm{C}$ which is also probably associated with the 
Table 3 Microscopic properties of neat crude oil and crude oil doped with $1000 \mathrm{ppm} \mathrm{CNX}$

\begin{tabular}{lllllll}
\hline Temp & Sample & \multicolumn{2}{l}{ Microscopic parameters } & \\
\cline { 3 - 7 } & & $\begin{array}{l}\text { Average feret } \\
\text { diameter }(\mu \mathrm{m})\end{array}$ & Aspect ratio & Circularity & Solidity & $\begin{array}{l}\text { Boundary } \\
\text { fractal dimen- } \\
\text { sion }\end{array}$ \\
\hline $20{ }^{\circ} \mathrm{C}$ & Neat oil & 7.68 & 1.82 & 0.81 & 0.85 & 1.44 \\
& Doped oil & 7.67 & 1.67 & 0.84 & 0.86 & 1.38 \\
$15{ }^{\circ} \mathrm{C}$ & Neat oil & 9.23 & 1.83 & 0.78 & 0.83 & 1.56 \\
& Doped oil & 7.87 & 1.67 & 0.83 & 0.85 & 1.45 \\
$10{ }^{\circ} \mathrm{C}$ & Neat oil & 10.3 & 1.83 & 0.76 & 0.82 & 1.62 \\
& Doped oil & 8.43 & 1.75 & 0.81 & 0.84 & 1.51 \\
\hline
\end{tabular}
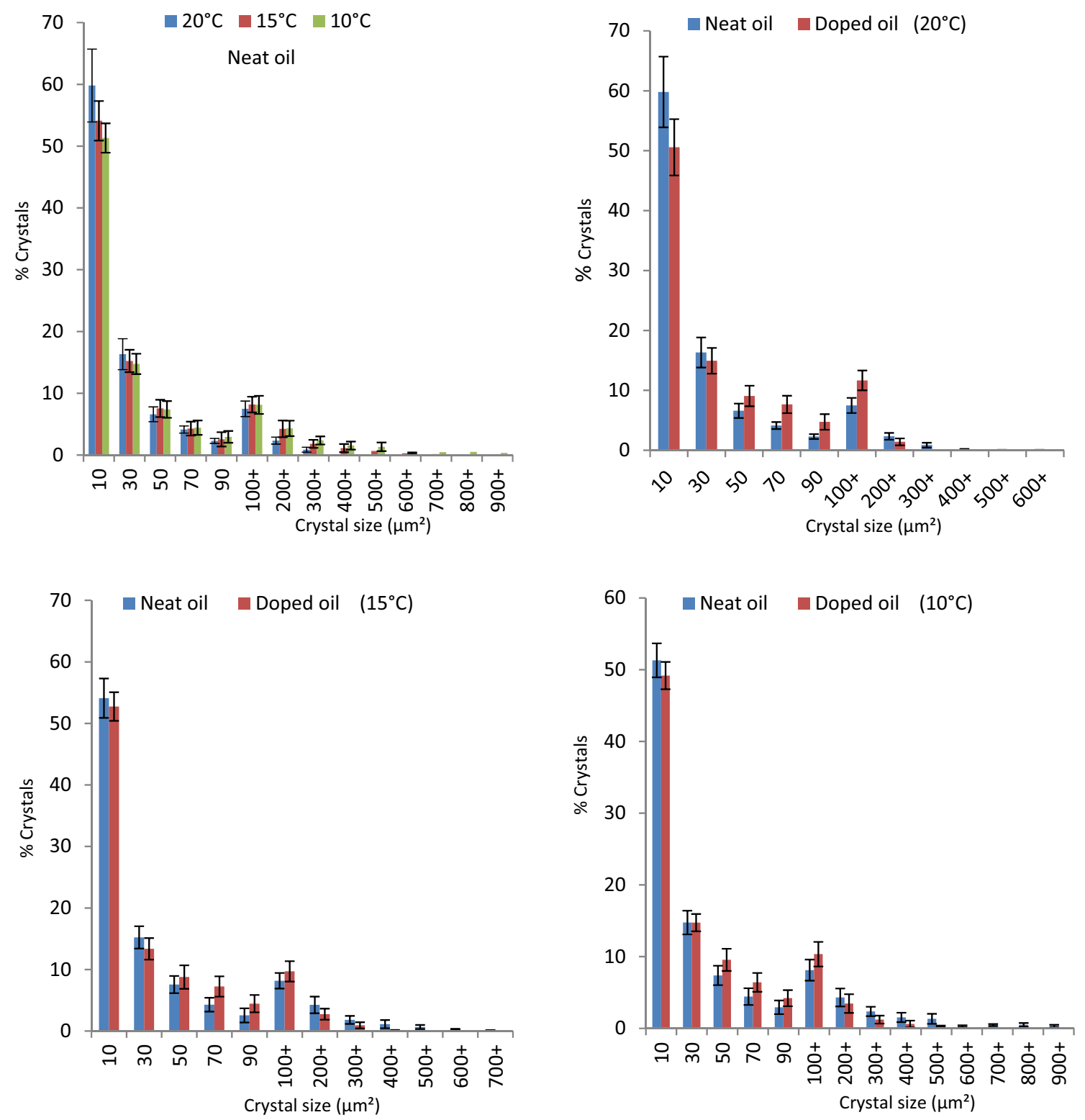

Fig. 7 Effect of temperature and additive on crystal size distribution 

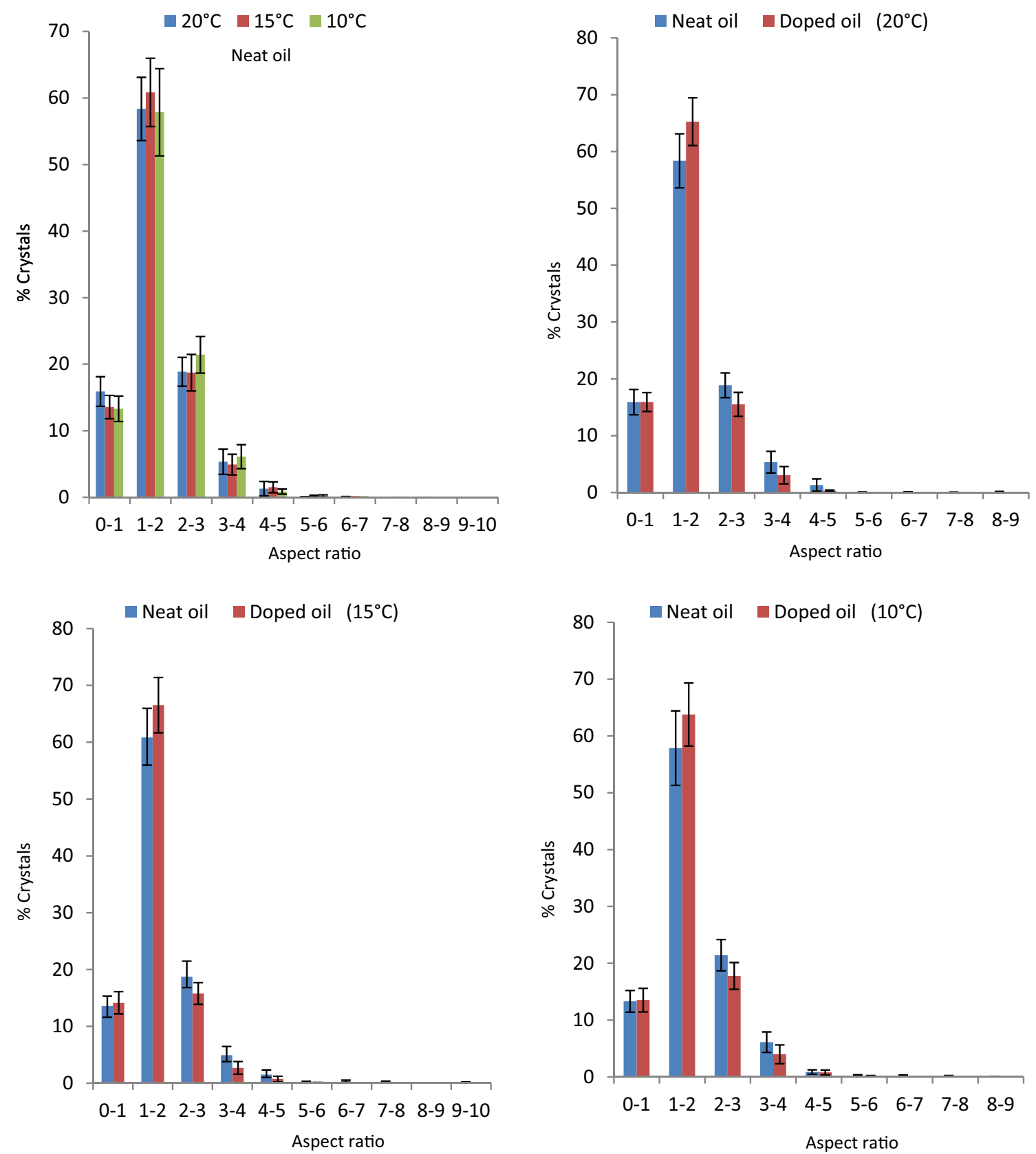

Fig. 8 Effect of temperature and additive on crystal aspect ratio distribution

peak number of crystals with aspect ratio of 1-2, observed at $15{ }^{\circ} \mathrm{C}$ in the aspect ratio distribution of neat oil as a function of temperature (Fig. 8). This is likely due to the dynamics of wax evolution in the neat oil and could be the result of a specific crystallization and or wax agglomeration event at that temperature. Notably, this high degree of crystal ruffling is not observed in doped crude oil irrespective of temperature. The presence of the additive suppresses crystal ruffling, preventing the evolution of low solidity crystals, thus resulting in an increase in the proportion of high solidity crystals at all temperatures. The changes in the morphology and microstructure of doped oil explain the pour point depressant effect of CNX. The ability of the doped oil to pour at lower temperatures is as a result of weakening of the wax networks formed in the oil. Small, round wax crystals with smooth and even surfaces are unfavorable to formation of strong wax networks in oil. Figure 10 shows the wax area fraction in neat and doped oil as a function of temperature. Wax area fraction was reduced by an average of $40.3 \%$ in doped oil, indicating that wax formation was inhibited in the presence of CNX. The wax area fraction is dependent on the wax amount in oil (equivalent to crystal count) and the wax 

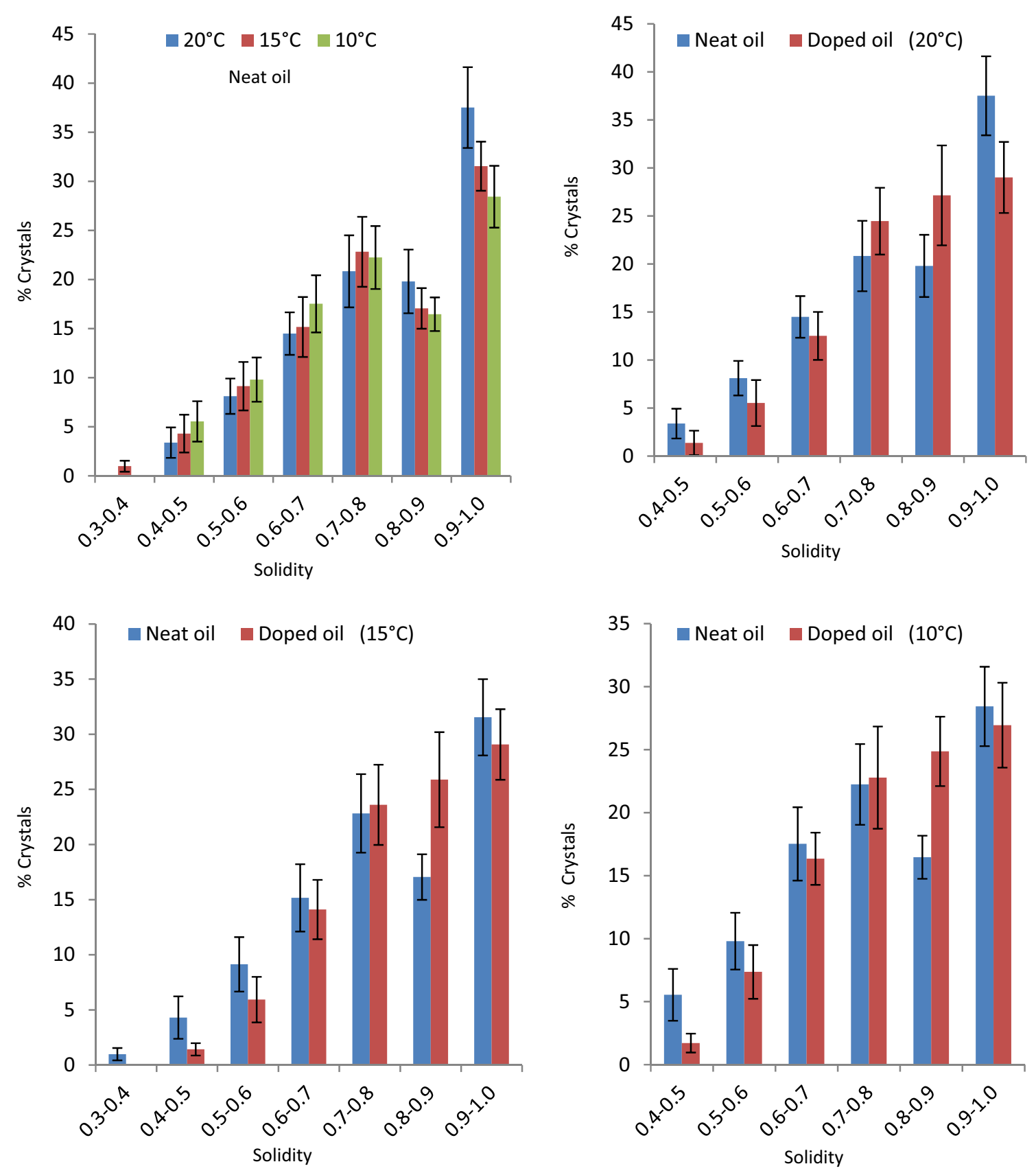

Fig. 9 Effect of temperature and additive on crystal solidity distribution

crystal size. As the temperature of the oil decreases the wax area fraction increases due to appearance of new wax crystals (increasing crystal count) and the growth of existing crystals. Oil viscosity increases with increasing wax area fraction. Optical microscopy data suggest that the pour point depressant mechanism of the sulfonated cashew nut shell liquid esteramine (CNX) is mainly via wax dispersion. Due to its similarity with paraffins, the 15-carbon aliphatic chain of CNX provides an avenue for interaction of additive molecules with wax in the oil, where the additive molecules likely adsorb onto incipient wax crystals. The polar groups of the additive molecule such as sulfonic acid, amine, hydoxyl and ester groups probably cause mutual electrostatic repulsion between small wax crystals onto which the additive molecules have adsorbed (Yao et al. 2020). These effects reduce wax agglomeration and may also hinder crystal growth resulting in smaller crystals and changes in wax morphology and microstructure. 


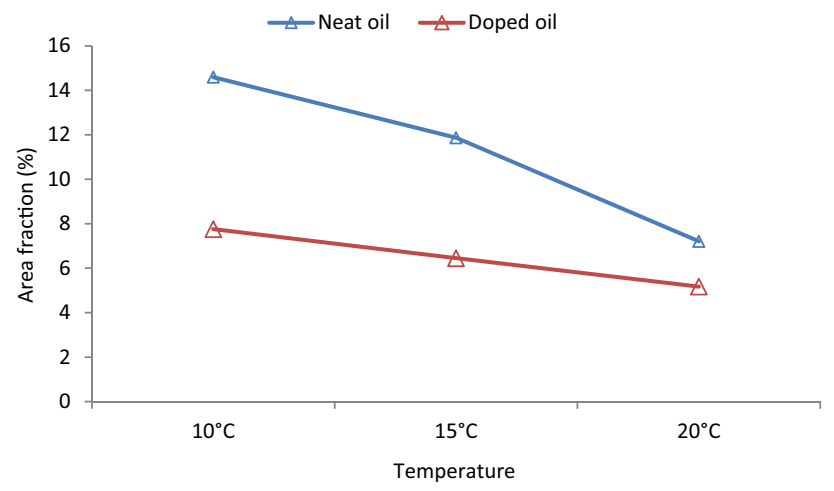

Fig. 10 Wax area fraction in neat crude oil sample and crude oil doped with 1000 ppm CNX

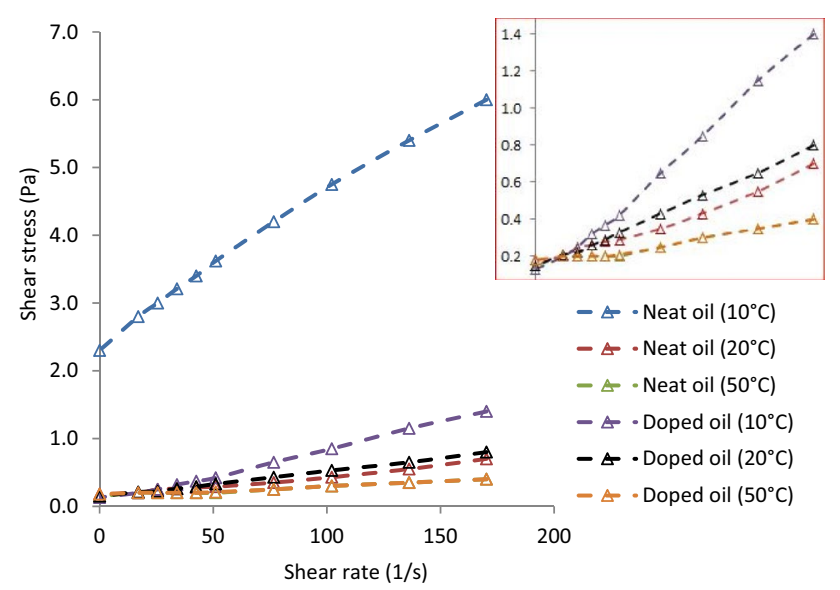

Fig. 11 Effect of shear rate on shear stress of neat crude oil and crude oil doped with 1000 ppm CNX

\section{Effect of CNSL derivative on crude oil flow properties}

The effect of the additives on oil flowability is presented in Figs. 11, 12, 13. Figures 11, 12 show the effect of shear rate on shear stress and viscosity of neat and doped oil, respectively, at $50{ }^{\circ} \mathrm{C}\left(\mathrm{WAT}+23.4^{\circ} \mathrm{C}\right), 20^{\circ} \mathrm{C}\left(\mathrm{WAT}-6.6{ }^{\circ} \mathrm{C}\right)$ and $10^{\circ} \mathrm{C}\left(\mathrm{WAT}-16.6^{\circ} \mathrm{C}\right)$. Figure 13 is the viscosity-temperature plot at constant shear rate.

At $50{ }^{\circ} \mathrm{C}$, oil temperature is much higher than the wax appearance temperature and no wax crystals have yet crystallized. At this temperature and at all temperatures above the WAT, the presence of the PPD has little effect on flow properties of the crude oil due to the absence of wax in the oil, only marginally increasing the shear stress and viscosity at high shear rates (Figs. 11, 12). This is probably due to viscosifying effect of the additive in oil at this temperature. At $20^{\circ} \mathrm{C}$, the temperature of the oil is below (but relatively near) the WAT and some crystallization has occurred

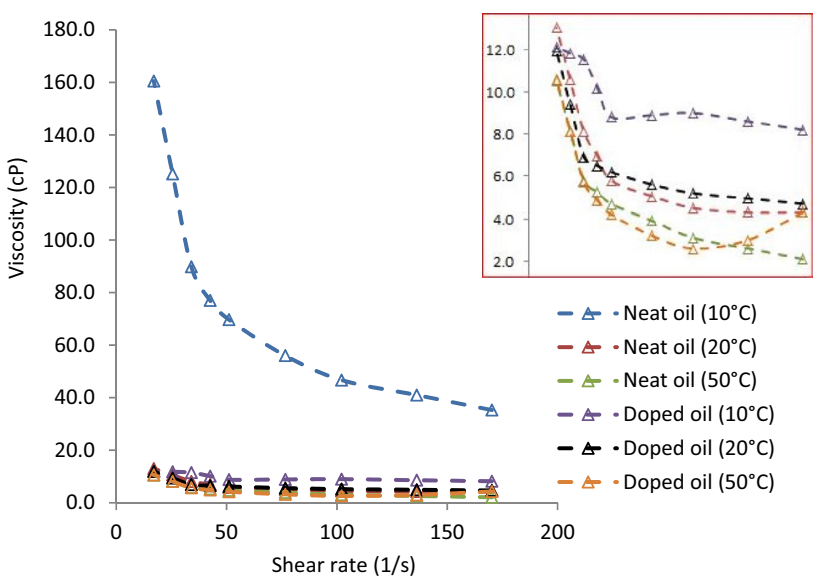

Fig. 12 Effect of shear rate on viscosity of neat crude oil and crude oil doped with 1000 ppm CNX

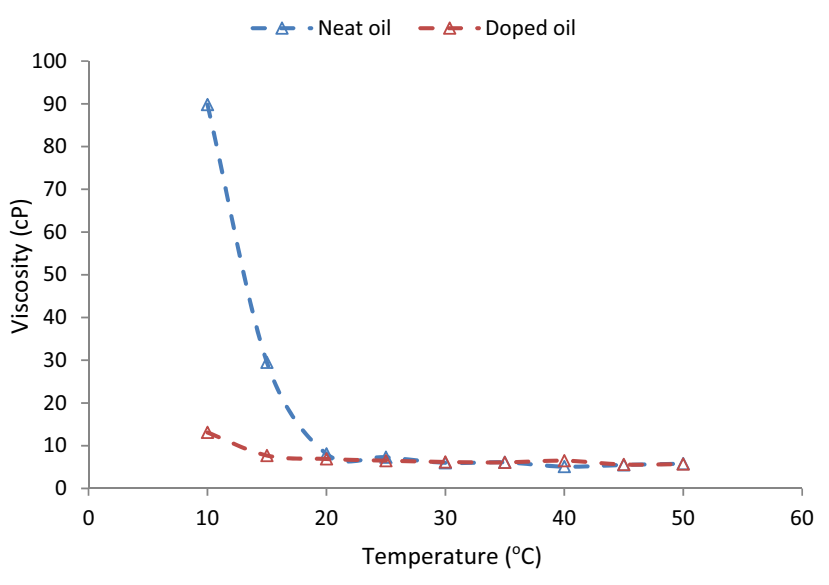

Fig. 13 Effect of temperature on viscosity of neat crude oil and crude oil doped with $1000 \mathrm{ppm}$ CNX; at constant shear rate $\left(51 \mathrm{~s}^{-1}\right)$

(Fig. 6) Addition of the PPD results in greater reduction in shear stress and viscosity of the oil, but only at lower shear rates. This may be as a result of the relatively weaker wax structures existing in the oil at this temperature which are easily destroyed at higher shear rates even in the absence of additives. At $10{ }^{\circ} \mathrm{C}$, the oil temperature is much lower than the WAT and extensive wax crystallization has occurred (Fig. 6). The shear rate-shear stress curve of neat oil is very steep, as the oil shear stress increases sharply with shear rate (Fig. 11). The shear stress is a measure of the resistance of the fluid to shear forces. The sharp increase in shear stress is due to the presence of high amount of large wax crystals in the oil at this temperature resulting in poor flowability.

The same inference can be made from the viscosity-shear rate plot (Fig. 12). Oil viscosity is elevated and shows higher dependence on the shear rate. Upon doping, the shear stress and viscosity of the oil at low temperature $\left(10^{\circ} \mathrm{C}\right)$ were on 
average reduced by $86.8 \%$ and $85.0 \%$, respectively, indicating dramatic improvement in oil flowability. The reduction in viscosity is as a result of lower internal friction in flowing oil arising from changes in morphology and microstructure of wax in doped oil. This is because small, rounded crystals with smoother even surfaces will experience less frictional resistance as they make contact with each other.

The viscosity-temperature curve at constant shear rate $\left(51 \mathrm{~s}^{-}\right)$shows that the presence of the additive has negligible effect on viscosity of the waxy oil when the oil temperature is above the WAT (Fig. 13). However, as the temperature decreases toward the experimental WAT (previously determined by CPM) an inflection occurs in the viscosity curve of the neat oil and the viscosity increases rapidly due to wax crystallization in the oil. The inflection point denotes the onset of wax crystallization, which is the wax appearance temperature. Notably, the temperature at the inflection point is lower than the wax appearance temperature determined by optical microscopy. This is because unlike optical microscopy, a reasonable amount of wax crystals needs to exist in the oil to cause a measurable change in oil viscosity. Furthermore, the inflection point in the viscosity-temperature curve of doped oil is lower compared to the neat oil. This indicates that at any temperature below the WAT, smaller amount of wax crystals exists in the doped oil relative to the neat oil. This supports the earlier observations (from microscopic data) of wax inhibition in doped oil based on reduction in wax area fraction. The wax inhibitive effects of the additive in doped oil prevent the rapid increase in viscosity observed in the neat oil in the temperature region below WAT $\left(<25^{\circ} \mathrm{C}\right)$, where the viscosity of the oil increases by about 50cP per degree Celsius drop in temperature, compared to $19 \mathrm{cP} /{ }^{\circ} \mathrm{C}$ in doped oil.

\section{Conclusions}

Natural cashew nut shell liquid was extracted and modified with diethanolamine and sulfuric acid. Addition of the sulfonated cashew nut shell liquid esteramine (CNX) to waxy crude resulted in depression in oil pour point and modification of wax crystal morphology and microstructure, resulting in improvement in oil flow properties. In the presence of the additive, the average Feret diameter, aspect ratio and boundary fractal dimension of wax crystals were reduced, while crystal circularity and solidity increased as smaller, rounder and more regular crystals with smoother, even surfaces were formed. Wax formation was inhibited in doped oil indicated by reduction in wax area fraction. The wax inhibitive and crystal modifier effects of the additive are due to interaction between additive molecules and wax. These interactions are likely via adsorption and dispersion. The improvement in low-temperature flowability of the waxy crude oil is attributable to the changes in wax crystal morphology and microstructure which reduces the internal friction within the oil and lowers its resistance to shear.

Acknowledgements The authors are grateful to Shell Petroleum Development Company (SPDC), Port Harcourt, for research support. Special thanks to the Production Chemistry team, particularly Eno-Obong Ntefreh for technical assistance.

Funding Not applicable.

Available of data and materials Not available.

Code availability Not applicable.

\section{Compliance with ethical standards}

Conflicts of interest On behalf of all the co-authors, the corresponding author states that there is no conflict of interest.

Open Access This article is licensed under a Creative Commons Attribution 4.0 International License, which permits use, sharing, adaptation, distribution and reproduction in any medium or format, as long as you give appropriate credit to the original author(s) and the source, provide a link to the Creative Commons licence, and indicate if changes were made. The images or other third party material in this article are included in the article's Creative Commons licence, unless indicated otherwise in a credit line to the material. If material is not included in the article's Creative Commons licence and your intended use is not permitted by statutory regulation or exceeds the permitted use, you will need to obtain permission directly from the copyright holder. To view a copy of this licence, visit http://creativecommons.org/licenses/by/4.0/.

\section{References}

Ajienka JA, Ikoku CU (1990) Waxy crude oil handling in nigeria: practices. Prob Prospect Energy Sour 12(14):463-478

Akinyemi OP, Udonne JD, Oyedeko KF (2018) Experimental study of utilization of plant seedoil as pour point depressant for nigerian waxy crude oil. IJSER 9(7):205-209

Azeem A, Kumar R, Pal B, Naiya TK (2020) Use of novel pour point depressant synthesizedfrom vegetable oil for waxy crude oil. Pet Sci Technol 38(3):185-193

Bai C, Zhang J (2013) Effect of carbon number distribution of wax on the yield stress of waxy oil gels. Ind Eng Chm Res 52:2732-2739

Banerjee S, Kumar R, Mandal A, Naiya TK (2015) Effect of natural and synthetic surfactant on the rheology of light crude oil. Pet Sci Technol 33:1516-1525

Chen G, Tang Y, Zhang J (2011) Synthesis and application of polyaminoamide as new paraffininhibitor from vegetable oil. Chem Cent J 5:82-84

Deng Q, Bai Y, Gu X, Chen G, Zhang Z (2016) Synthesis of polyhydrazide from canola oil and use as a flow improver for crude oil. Advances in Engineering Research 103:281-285

Eke WI, Achugasim O, Ofordile SE, Ajienka JA, Akaranta O (2019a) Influence of heavy organics composition on wax properties and flow behavior of waxy crude oils. CSIJ 27(2):1-12

Eke WI, Achugasim O, Ajienka J, Akaranta O (2020) Glycerol-modified cashew nut shell liquid as eco-friendly flow improvers for

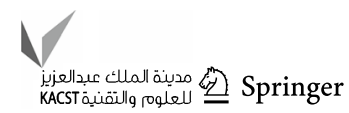


waxy crude oil. Pet Sci Technol. https://doi.org/10.1080/10916 466.2020.1849284

Eke, WI, Achugasim O, Ofordile SE, Ajienka J, Akaranta, O (2019b) Performance evaluation of cashew nut shell liquid CNSL as flow improver for waxy crude oils. In: SPE-198721 MS. In: Nigeria Annual International Conference and Exhibition, Lagos

Fasesan SO, Adewunmi OO (2006) Wax variation in some Nigerian Oil wells in the Delta field. Pet Sci Technol 21(1-2):91-111

Gandhi T, Patel M, Dholakiya BK (2012) Studies on effect of various solvents on extraction of cashew nut shell liquid (CNSL) and isolation of major phenolic constituents from extracted CNSL. J Nat Prod Plant Resour 2(1):135-142

Garcia MDC, Carbognani L, Orea M, Urbina A (2000) The Influence of alkane class-typeson crude oil wax crystallization andinhibitors efficiency. J Pet Sci Eng 25:99-105

Gedam PH, Sampthkumaran PS (1986) Cashew nut shell liquid: extraction. Chem Appl Progr Org Coat 14:115-157

Huyen QTM, Chau NGM, Tuan NBH, Thoa DTK, Khanh NV (2012) Synthesis routes forpotential pour point depressants from cashew nut shell liquids. J Cataly Adsorp 1:176183

Huyen QTM, Khanh NV (2014) Synthesis of crude oil pour point depressants via polycondensation of cashew nut shell liquid. Petrovietnam 6:48-52

Kriz P, Andersen SI (2005) Effect of asphaltenes on crude oil wax crystallization. Energy Fuels 19:948-953

Kumar R, Banerjee S, Kumar N, Mandal A, Naiya TK (2015) Comparative studies on synthetic and naturally extracted surfactant for improving rheology of heavy crude oil. Pet Sci Technol 33:1101-1109

Lashkarbolooki M, Esmaeil-zadeh F, Mowla D (2011) Mitigation of wax depositon by waxcrystal modifier for kermanshah crude oil. J Dispers Sci Technol 32:975-985

Mozaffari S, Tchoukov P, Atias J, Czarnecki J, Nazemifard N (2015) Effect of asphaltenes aggregation on rheological properties of diluted athabasca bitumen. Energy fuels 29(9):5595-5599

Mozaffari S, Tchoukova P, Mozaffari A, Atiasd J, Czarneckia J, Nazemifard N (2017) Capillary driven flow in nanochannels - Application to heavy oil rheology studies. Colloids Surf. A 513:178-187

Odutola TO, Idemili CA (2020) Effect of poly (ethylene butene) and nano aluminum oxide blend on the viscosity of Nigerian crude oil. J Pet Explor Prod Technol 10:2531-2539

Paso K, Senra M, Yi Y, Sastry AM, Fogler HS (2005) Paraffin polydisersity faciitates mechanical gelation. Ind Eng Chem Res 44:7242-7254

Ragunathan T, Husin H, Wood CD (2020) Effect of crude palm oil and crude palmkernel oil upon wax inhibition. ACS Omega 5(31):19342-19349
Ridzuan N, Subramanie P, Uyop MF (2020) Effect of pour point depressant (PPD) and the nanoparticles on the wax deposition, viscosity and shear stress for Malaysian crude oil. Pet Sci Technol. https://doi.org/10.1080/10916466.2020.1730892

Sarica C, Panacharoensawad E (2012) Review of paraffin deposition research under multiphase flow conditions. Energy Fuels 26:3968-3978

Senra M, Panacharoensawad E, Kraiwattanawong K, Singh P, Fogler HS (2008) Role of n-alkane polydispersity on the crystallization of n-alkanes from solution. Energy Fuels 22:545-555

Sun Z, Zhang J, Jing G, Liu Y, Liu S (2020) Research progress and discussion of waxy crudepour point depressants: a mini review. Recent Innovat Chem Eng 13(4):323-331

Taheri-Shakib J, Shekarifard A, Naderi H (2018) Characterization of wax precipitationiniranian crude oil based on WAT: the influence of electromagnetic waves. J Pet SciEng 161:530-540

Theyab MA (2018) Wax deposition process: mechanisms, affecting factors and mitigationmethods. Open Access J Sci 2(2):112-118

Tyman JH (1976) Determination of the components phenols in natural and technicalcashew nut-shell liquid by gas-liquid chromatography. Anal Chem 48(1):30-34

Tyman JHP, Johnson RA, Muir M, Rokhgar R (1989) Extraction of natural cashew nut-shell liquid from the cashew nut ( Anacardium occidentale). J Am Oil Chem Soc 66(4):553-557

Wang W, Huang Q, Liu Y, Sepehrnoori K (2015) Experimental study on the mechanism of wax removal during pipeline pigging. In: SPE annual international conference and exhibition, Texas

Wei B (2015) Recent advances in mitigating wax problem using polymeric wax crystal modifier. J Pet Explor Prod Technol 5(4):391-401

Yang F, Zhao Y, Sjöblom J, Li C, Paso KG (2014) Polymeric wax inhibitors and pour point depressants for waxy crude oils: a critical review. J Dispers Sci Technol 36(2):213-225

Yao B, Chen W, Li C, Yang F, Sun G, Wang G, Xu H (2020) Polar asphaltenes facilitate theflow improving performance of polyethylene-vinyl acetate. Fuel Process Technol 207:106481

Zhang J, Wu C, Li W, Wang Y, Han Z (2003) Study on the performancemechanism of pour point depressants with differential scanning calorimetry and xray diffraction methods. Fuel 82:1419-1426

Publisher's Note Springer Nature remains neutral with regard to jurisdictional claims in published maps and institutional affiliations. 